\title{
GENRE-SPECIFIC PERSUASION IN ORAL PRESENTATIONS: ADAPTATION TO THE AUDIENCE THROUGH MULTIMODAL PERSUASIVE STRATEGIES.
}

\begin{abstract}
Product pitches, research dissemination talks and conference presentations are three oral genres that share important characteristics. Previous literature has described them as multimodal and persuasive oral genres and has shown that speakers resort to multimodal persuasive strategies to achieve their communicative goals. However, they are used in different contexts, which is likely to affect their use of multimodal persuasion, and raises questions as to how genre-specific persuasion is. The aim of this paper is to explore how speakers adapt their multimodal persuasive efforts to the communicative situation established in each genre, and how this is reflected multimodally. This study combines multimodal discourse analysis and ethnographic methods. The results suggest that speakers multimodally convey a different relationship with the audience in each genre.
\end{abstract}

Key words: presentations, multimodality, persuasion, oral genres, speaker-audience relationship

\section{Introduction}

$\underline{\text { Persuasion in oral presentations: the importance of the audience }}$

Most studies on persuasive public speaking consider adaptation to the audience as a prerequisite to achieve persuasion. Benoit \& Benoit (2008) stress a number of audiencerelated factors that need to be taken into account during preparation for a presentation: their knowledge, their interest and their attitude both towards the topic and the speaker. They also suggest that speakers need to show the audience how they can be directly affected by the topic in order to raise interest.

Simons \& Jones (2011), share this audience-focused approach to persuasion. They claim that speakers need to be aware of who their audiences are and what matters to them, and they advise to shape presentations according to the audience's attitude to the topic and the communicative situation. They use the umbrella term 'coactive 
persuasion' to refer to the different resources that can be used to prompt persuadees to accept a position or proposal for action. Interestingly, they point out that these resources are multimodal: speakers can use intonation, face expression, gestures, etc. in order to achieve coactive persuasion.

Multimodality and persuasion in product pitches, research dissemination talks and $\underline{\text { conference presentations }}$

The study presented in this paper is concerned with three oral genres: product pitches, research dissemination talks and conference presentations. The first are short presentations used in business contexts to introduce a product or service to potential buyers or funders. The conference presentation can be classified as an oral academic genre used within academia to spread research among fellow researchers. Research dissemination talks share the purpose of the conference presentation, but differ in the type of audience, since they are meant to disseminate research to a lay audience. The present study deals with a particular type of research dissemination talks, i.e. TED talks.

These oral genres have three important characteristics in common: 1) they all include a monologic section addressed to an audience, 2) they use a variety of semiotic modes to convey meaning (i.e. they are multimodal), and 3) they are persuasive. Especially, their multimodal and persuasive nature has been discussed in previous literature (Author, 2019a, 2019b). Some particularly relevant studies are mentioned in the following paragraphs.

The presentation of the iPhone is an example of a product pitch that has been extensively studied. Kast (2008) identifies an interesting interplay of modes in this presentation, such as rhetorical figures of speech supported by non-verbal communication and visual aids, or argumentations which are replaced by multimedia aspects. Niebuhr et al. (2016) reveal characteristics in the use of intonation that differentiate Jobs' public addresses (e.g. a high pitch range, a particularly varied pitch contour, varied loudness, and short tone units), demonstrating the extensive contribution of this semiotic mode.

The important role of persuasion in product pitches is evidenced in the numerous recommendations by practitioners with first-hand experience with the genre, such as Rackham (1998), Burzynski’s (2013) Clemence Lepers' (2015) or Woods et al. (2014). 
These experts agree that product pitches are inherently persuasive, and that presenting a product as a (better) solution to a problem that directly affects the audience is one of the defining traits of product pitches.

Within research dissemination talks, TED talks have received increasing attention. Caliendo (2014) and Compagnone (2015) acknowledge their multimodal nature noting that this genre combines different semiotic modes (i.e. spoken, written, video and audio). McGregor et al. (2016) find that intonation is used in this genre to convey the speaker's attitude towards the content and the audience. Similarly, Masi (2016) shows the crucial contribution of deictic and metaphoric gestures in a corpus of TED talks.

Turning now to persuasion in research dissemination talks TED curator Chris Anderson, (2013) considers that a key to a successful talk is to get the right connection with the audience. Assuming that the audience has more knowledge and interest than they actually do or using specialised language that excludes them will make you fail as a speaker. The clue is to introduce your topic, explain why you care deeply about it and convince the audience that they should care too. Results of later studies (Caliendo, 2014; Scotto di Carlo, 2014; Compagnone, 2015) have corroborated these views. For example, a comparative study by Scotto di Carlo (2014) has shown how persuasive appeals through ethos, pathos and logos are remarkably different in a TED talk and a conference presentation dealing with the same topic and delivered by the same speaker. In the TED talk the speaker uses a variety of resources to engage the audience and create proximity. Furthermore, the speaker convinces through 'trustworthiness' (i.e. ability to be consistent with the message) and 'similarity' (i.e. ability to make the audience identify with you) in contrast to 'authority' or 'reputation'. Finally, in the TED talk the speaker uses examples, metaphors and visuals to enhance the comprehension of the message, while in the conference presentation the use of specialised terminology has the opposite effect.

The multimodal character of conference presentations is evidenced by numerous authors like Carter-Thomas and Rowley-Jolivet (2003) or Morell (2015). Rendle-Short (2006) has shown how speakers use a variety of kinesic and prosodic modes to indicate orientation to the audience and mark the macrostructure of their discourse. This author also points out that every presentation is designed for a particular audience, which in Conversation Analysis (CA) is called the principle of recipient design, or "the speakers 
ability to take account of who the recipient is and what they know, as well as referring to the ability of the speaker to continually monitor the recipient and to modify their talk in response to the interactional needs"'(Rendle-Short 2006: 12)

In what concerns persuasion in conference presentations, Rowley-Jolivet (1999), CarterThomas and Rowley-Jolivet (2003) and Rowley-Jolivet and Carter-Thomas (2005) have claimed that conference presentations are inherently persuasive. Räisänen (2002) agrees with this claim and points out that the primary aim of a conference presentation is to publicize, critically discuss and ratify research. This idea is also supported by Swales and Burke (2003), Wulff et al. (2009) or Querol-Julián (2011), who classify the genre of conference presentations within the 'contingent' repertoire of academic discourse.

The semiotic modes included in the analysis

In view of the prominent multimodal and persuasive character of the genres that concern this study, I have undertaken an ethnographic and Multimodal Discourse Analysis (MDA) to probe into the use of multimodal persuasive strategies in them. The analysis caters for the semiotic modes 'words', 'intonation' and 'gestures'. These modes do not represent the entire semiotic complexity of oral presentations, but they were selected because 1) they are virtually inevitable in oral discourse, and 2) they were hypothesized to have a prominent effect on persuasion. In the following paragraphs I will provide a brief explanation of each mode.

I use the term words to refer the semiotic mode that includes the verbal-linguistic material used by speakers (as opposed to paralinguistic or kinesic aspects). The term 'words' is arguably rather unspecific, but I have preferred it over other more specific terms because it describes more accurately the way I conceive this mode. The term 'verbal' would be misleading because it can also include material that is produced verbally but which is non-linguistic, and therefore would fall into 'paralanguage'. The term 'lexical' would be too restrictive, because under the semiotic mode words I also consider aspects such as grammatical structure, which is usually considered out of the scope of lexis. The term 'language' would be far too generic, because language can be considered a macro-system including paralinguistic and kinesic features. Finally, 'speech' would also be misleading in the context of this study because it can be interpreted as a synonym of 'presentation' or 'public address'. Therefore, the mode words include 'lexis' (vocabulary choice), 'grammar', 'style' and 'register'. Within 
'lexis', I am particularly interested in aspects such as evaluative vocabulary, intense language, direct addresses to the audience, lexical creativity and references to the event, which can prompt a particular response from the audience and contribute to rapport (Hyland, 1997; Pomerantz, 1986; Lakoff, 1982, Bhatia, 2005 Bamford, 2007, 2008). The use of specific 'grammatical structures' can facilitate understanding (e.g. through ordering or listing) or prompt a particular response. Thirdly, some 'stylistic devices' can make the message more memorable. For example repetitions, symmetrical structures and three part lists (Bowring et al, 2013) can make the text memorable. Likewise narratives (Bamford, 2008; Boker, 2006, 2007; Thompson, 2002) and examples (Lichinksi, 2008) can present the information as closer, more vivid and more relevant to the audience. Finally, specific choices in 'register' can contribute to persuasion, in particular when they are unexpected. As pointed out in previous research (Petty and Cacciopo, 1997; Perloff, 2003), forewarning is a persuasion killer, because it activates the recipients mind and stirs potential counterarguments: it activates elaboration-based persuasion in a way that can backfire for the speaker.

Intonation has been described as "the use of patterns of pitch to convey different kinds of meaning in discourse" (Dalton and Seidlhofer, 1994: 176). It can be seen as a tool facilitating the flow of discourse and helping the negotiation process involved in every communicative interaction. Discourse Intonation claims that speakers make meaningful intonational choices to project their assumptions and intentions during the communicative process (Brazil, 1997).

According to Kendon (2004: 7) 'gesture' is "visible action when it is used as an utterance or as part of an utterance". Literature agrees that gestures can be used to point out, to represent an aspect of the content or to refer to the structure of discourse. Kendon (2004) suggests that it is possible to group gestures with similar kinesic characteristics into families sharing a common semantic theme. The 'open hand prone' (OHP) family groups together gestures realised with an open hand and palm facing down, and they share the semantic theme of halt or stop. The 'open hand supine' (OHS) family comprises gestures made with the palm of the hand facing up that convey offering or willingness to receive something. Poggi and Pelachaud (2008) have studied how these gestures are used in political speeches to convey honesty and benevolence and make people more prone to accept the message. Finally, differences in meaning can be spotted in different ways of pointing (e.g. pointing with the index finger and palm 
down indicates that the exact location is relevant, while pointing with the palm up and hand open suggests we offer the object referred to or present it for inspection).

\section{Persuasive strategies realised multimodally}

Triangulating input from literature with the results of multimodal analysis and ethnographic analysis, Author (2018) identified a series of persuasive strategies that are realised through the semiotic modes explained in the previous paragraphs. The process of identifying the strategies was cyclical rather than linear. Some strategies were first suggested by the literature on persuasion and later revealed to be realized multimodally through the MDA and ethnographic interviews. Other strategies were first suggested by the MDA and ethnographic analysis and later revealed to have a persuasive effect by the literature review.

These strategies constitute an interesting tool to study the multimodal behaviour of speakers in a systematic way. In addition, they facilitate the comparison of persuasion across the genres. A full account of these strategies can be found in Author (2019a). The following list offers a brief definition of the strategies that are explicitly discussed in this paper:

I. 'Attention getting' is used to raise and maintain the interest of the audience.

II. 'Emphasis' is used to highlight parts of the message to make them more salient.

III. 'Evaluation' is found when speakers assess something and implicitly invite the listener to accept this assessment.

IV. 'Processing aids' are resources that make the message easy to understand, such as visual metaphors materialised through gestures.

V. 'Projection of the context of interaction' refers to the way speakers can present information so that it is perceived in a certain way, e.g. as agreed upon and no longer open to discussion, or as the only possible option.

VI. 'Rapport' refers to a relationship of sympathy and mutual understanding with the audience.

These multimodal strategies contribute to create some persuasive effects generally accepted in previous literature on persuasion. For example, they can make the message simple, unexpected and emotional (Heath and Heath, 2007)

In this introduction I have highlighted the importance of the audience in persuasion. I have also stressed the multimodal and persuasive nature of the three oral genres that 
concern this study. In the following section I use a MDA and ethnographic approach to analyse speakers' use of multimodal persuasive strategies, focusing on words, intonation and gestures as semiotic modes. The aim of this analysis is to explore: 1) how speakers adapt to their specific audiences, and 2) how this is reflected in their use of multimodal persuasive strategies.

\section{Corpus description and methodology}

Three types of presentations comprise the corpus of this study: product pitches, research dissemination talks and conference presentations. They belong to different discourses: business and academic. Part of what makes them comparable is the so-called promotionalization or marketization of academic discourse. As Hyland (2009) claims, "while academic ideologies may claim that research is driven by the disinterested pursuit of truth, individual academics generally put peer approval and institutional recognition high on their list of motivating forces" (Hyland, 2009: 14). Given this trend, it is plausible to expect intertextual and interdiscursive relationships among these presentations. In the building of the corpus I followed Sinclair's (2005) guidelines for spoken corpus design. The first of these guidelines claims that content must be selected according to communicative functions and regardless of the language they contain. For this reason the presentations were not selected on the grounds of specific linguistic, paralinguistic or kinesic features, but according to a common persuasive communicative purpose: convincing an audience of the validity of a product or a piece of research. From the point of view of genre analysis, it is particularly interesting to study how persuasive language differs or overlaps in them, and it provides a solid tertium comparationis (Chesterman, 1998).

The product pitches were video recorded (after consent had been granted) during the closing event of a project in which university students collaborate with companies in the design and launch of new products. In this event speakers pitch the products they have conceived in 3 minutes. The research dissemination talks were videoed during a university TED contest in which researchers present their work to a layman audience in 6 minutes. These two events were framed as contests. The conference presentations were held at an international symposium on business discourse. The conference lasted two days and each presentation was allotted 20 minutes. In the three events there was time for Q\&A session after each presentation, but this was not included in the analysis 
in order to keep the focus on the monologic part. Five presentations in each event were selected on the basis of the following criteria:

i) Good quality of image and sound of the recording;

ii) Availability of the complete presentation in the recording;

iii) Availability of speakers for ethnographic interviews.

All the speakers are proficient users of English and 3 speakers have English as their mother tongue. Interestingly, the difference in native language did not seem to have a noticeable influence. In fact, the winning product pitch and research dissemination talk were delivered by non-natives.

Out of this corpus of 15 presentations two extracts were selected in each of them (i.e. a total of 30) that were more intense in persuasive efforts from the speakers compared to the rest of the presentation. The length of the excerpts varies in each case for the sake of completeness. The excerpts were selected exclusively on the grounds of strong persuasive effort and not because they illustrated a particular use of words or a specific paralinguistic or kinesic feature. The position of the excerpts within the presentations was not taken into account as a selection criteria. However, the results show a predominance of excerpts belonging to introductions, which indicates the importance of persuasion in these initial sections of the presentations. The selection was aided by ethnographic interviews with the speakers and triangulated with the opinions of three other researchers. The size of the corpus does not allow for quantitatively-based generalisations, but it is valid for qualitative analysis. It is also in line with previous multimodal studies, which due to their minute level of detail and the lack of automating tools cannot afford the use larger corpora. (Querol-Julián, 2011; Morell, 2015). More details about the corpus, as well as the methodology outlined in the following paragraphs, can be found in Author (2018), Author (2019a) and Author (2019b).

The methodology I have used in this study combines MDA with ethnographic methods. Two rounds of ethnographic interviews were carried out. After each event the researcher interviewed the speakers in face-to-face, semi-structured interviews that enquired about their previous knowledge and experience with the genre, their attitudes to public speaking and their satisfaction with their performance. This information proved useful to better interpret their use of modes and identify potentially persuasive 
parts. Later, after the MDA analysis, a second interview was carried out using a 'playback methodology' and including stimulated recall (Norris, 2004; Norris, 2011: 59). The speakers watched the video of their presentation. Then they were asked to pay attention to particular uses of words, intonation and gestures that the MDA had revealed as potentially relevant for persuasion and they were asked to provide their interpretations. Finally, these comments were contrasted with the results of the researcher. This exchange contributed to a greater objectivity in the interpretation of results. Firstly, the occasional divergent interpretations from speakers were integrated in the analysis and secondly, the comments of the speakers also helped to keep the focus on the overall picture and adjust the relevance assigned to each mode.

The MDA analysis was aided by the phonetic analysis tool PRAAT and the multimodal annotation tool ELAN. The annotation of intonation follows Discourse Intonation (DI) conventions (Brazil, 1998). The annotation of gestures is based on the taxonomies proposed by McNeill (1992), Kendon (2004), Bavelas et al. (1995) and Querol-Julian (2011). Tables $1 \mathrm{a}$ and $1 \mathrm{~b}$ provide more details of these annotation systems.

\section{<INSERT TABLE 1a HERE>}

\section{$<$ INSERT TABLE $1 \mathrm{~b}$ HERE $>$}

The annotation of words does not follow a pre-defined set of categories. The main reason for this is to avoid overestimating words as a mode, which would lead to restricting the analysis of the other modes to instances in which they co-express a particular meaning simultaneously with words. In addition, speakers are generally very capable of accounting for their use of words, but find it harder to explain their use of intonation and gestures because they are less conscious of them. Thus, the use of a systematic classification system was necessary to facilitate discussion during the interviews, but it was not necessary in the case of words. Figure 1 provides an example of the annotation process with ELAN.

\section{$<$ INSERT FIGURE 1 HERE $>$}

\section{Results and discussion}

The analysis of the corpus of presentations suggests that speakers target at a different relationship with the audience depending on the genre, which can be described as 
follows: The focus of the product pitch is to presents a product as a solution to a problem that the audience needs to solve. The research dissemination talk, on the other hand, tries to show research as relevant and even life-changing for the audience. Finally, in the conference presentation the focus seems to be on fitting in the event and the community as legitimate and competent members. This results in a different use of multimodal strategies in each case. I would like to illustrate this trend comparing three excerpts (one for each genre) in the following subsections.

\section{The product pitch (PP)}

In this pitch the speaker is presenting an application to assess apps, and he does it identifying a need that this product can cover. Table 2 shows the orthographic transcript.

\section{$<$ INSERT TABLE 2 HERE $>$}

The speaker starts by addressing the audience using the pronoun ' $y o u$ ', and employing emotional language ('care', 'feel'). He tries to present his product in concrete rather than abstract terms, by including the members of the audience into a narrative that illustrates the problem he is trying to solve. This is in line with previous research on the persuasive appeals of narratives and examples that can bring the topic closer to the audience (Thompson, 2002; Lichinsky, 2008; Bowker, 2006, 2007). At the same time he uses beats with an extended finger pointing to the audience (see figure 2) to get them involved and convey the idea that they are directly affected by the problem presented (your app may be delivering a bad experience for customers). The speaker uses fall tones in most of the units (see Table 3), which indicates that he is treating the information in this extract as mainly new. This use of intonation is a powerful awareness raising tool towards the problem and market gap, but it also contrasts with the way he is lexically framing the information as something that is potentially familiar to the audience, since he seems to be asking them to picture a common situation with "you have an app". The speaker confirmed during the interview that he actually expected the audience to feel identified so that a sense of 'shared conspiracy' is created, but also agrees that part of the intention is raising awareness about this potential jeopardy.

$<$ INSERT FIGURE 2 HERE> 


\section{$<$ INSERT TABLE 3 HERE $>$}

In fact the speaker described his gestures as 'scolding' and agrees that they are meant to prompt people to consider a potential danger and react to it. He also explained that he decided to adopt this approach because he wanted to differentiate himself from the majority of marketing messages that focus on boosting positive qualities and in this way surprise the audience. Indeed, previous literature suggests that persuasion is more effective when it is unexpected (Petty and Cacciopo, 1997; Perloff, 2003).

His consistent use of repetition is also quite remarkable, for example in nouns and verbs that carry key concepts in his message, such as 'important', 'business', 'care', 'users' and 'app'. In particular the repetition of the word 'app' directs attention to the product and the market gap. There are further repetitions that have an intensifying effect and provide the text with a symmetrical structure (Bowring et al., 2013) that makes it more memorable ("But sometimes, you deliver a bad experience. Sometimes, you deliver a real bad experience”). These repetitions are mostly synchronous with prominences and beats.

The extract closes with an extreme negative evaluation ("real bad experience") which is emphasized by the prominence in 'real' in unit 8 and a beat gesture. With this evaluation the speaker is showing a potential danger that can be avoided with this product and appeals to fear. Research on persuasion suggests this strategy is particularly effective when the potential negative effect is perceived as real and the action required to avoid this negative effect as feasible (O’Keefe, 2002; Perloff, 2003; Simons \& Jones, 2011).

In this multimodal ensemble the use of pronouns, emotional language, narratives repetitions and evaluative language are all ways to enact the strategies rapport, evaluation and emphasis through words, the beating gestures contribute to the strategies emphasis and rapport (when they additionally point at the audience), and intonation (fall tones and prominences) serves the strategies projection and emphasis. The multimodal ensemble is represented in figure $3 \mathrm{a}$ (the size of the balloons represent the frequency of use of each mode). With these multimodally realised strategies the speaker tries to present a market gap that his product can fill. He also makes his presentation memorable, since repetitions and parallel structures make it easy to remember, and surprising because he uses a negative framing that differentiates the message from the 
general trend in marketing. The use of strategies is shown in figure $3 \mathrm{~b}$ (a value of 1 is assigned to each modal realisation: words $=1$, intonation $=1$ and gestures $=1$ )

\section{<INSERT FIGURE 3a HERE> <INSERT FIGURE 3b HERE>}

These choices are consistent with some ideas the speaker reported during the interview, mainly that it was important for him to sound 'genuine', and that the key to a good pitch is to think about the "what's in it for the audience". In his own words you have to focus on "why would anyone be interested in this" because "if the why doesn't resonate with them then they won't care about any other technical aspect".

\section{The research dissemination talk (DT)}

In this research dissemination talk the speaker explains his research on nanoparticles. Table 4 shows the orthographic transcript:

\section{$<$ INSERT TABLE 4 HERE $>$}

The speaker starts the presentation with an informal salutation and consistently uses the personal pronouns 'you' and 'your' to make the audience feel involved and build rapport. He gets the attention of the audience using lexical creativity: he plays with the meaning of the noun 'kiss' and verb 'kissing' to introduce the acronym KISS (keep it simple, but not stupid). According to the speaker the acronym was a well-planned hook to draw the attention of the audience, and he consciously repeated it several times to let it sink in. Simultaneously, he uses different deictic gestures to point to the audience. First he points with an extended finger (see figure 4a), selecting specific members of the audience in a way that is not expected in this communicative situation. This breaking of the rules raises interest and sets a humorous and relaxed tone. As the speaker explained during the interview, his intention was to create "a very personal connection" with the audience and "make them awake", and he was aware of the surprising effect it had on them.

The speaker also selects words that highlight the relevance of his research for the members of the audience and make them feel closer to the topic, like "your own experience". In addition, he uses intense language such as "revolutionise (...) your life". This is in line with findings by Bowker (2006) and Bamford (2007), which emphasize the role of affective force in business discourse, and with Benoit \& Benoit (2008), 
Simons \& Jones (2011) or Anderson (2013), which emphasize the importance of making the audience care. It is also interesting how the speaker postpones the specification of the technique that can "revolutionise the chemical industry" to create intrigue (which contributes to the strategy attention getting). At the same time, he points to the audience in a more generic way with open hand gestures that he considered would not be aggressive and would inspire confidence (see figure $4 b$ ).

\section{<INSERT FIGURE 4a HERE> <INSERT FIGURE 4b HERE>}

Intuitively, the speaker seems to share Petty and Cacciopo's (1977) interpretation of open hand gestures. These gestures are synchronous with "Your own experience" and "your life" and visually specify whose experience/life he is referring to, once more building rapport and enhancing understanding (gestural processing aids). It is remarkable that 'own' in "your own experience" and 'your' in 'your life' are prominent (see table 5 below), adding emphasis and contributing to the effect of the synchronous gestures. The speakers' interpretation of these gestures is more pragmatic than referential, although he agrees that he was also clarifying the referent in "your own experience" and "your life".

\section{$<$ INSERT TABLE 5 HERE $>$}

In line with the findings of Scotto di Carlo (2014), the speaker in this talk enhances comprehension (note the consistent use of 'simple' and 'very simple' as processing aids through words) and tries to convince through similarity rather than authority ("your own experience”).

The multimodal ensemble in this extract is represented in figure 5a.

In sum, the speaker in this presentation gets the attention of the audience and builds rapport using words and gestures that can be considered unusual and surprising in this communicative situation. In addition, intonation and words are used to provide emphasis to certain parts of the presentation and gestures and words are also used as processing aids to facilitate understanding. As a result the message is made memorable and engaging, and the speaker makes himself likeable as a presenter, which is likely to make the audience more prone to accept his ideas. The use of strategies is summarized in figure $5 b$. 
$<$ INSERT FIGURE 5a HERE > <INSERT FIGURE 5b HERE>

\section{The conference presentation $(\mathrm{CP})$}

The third example is the opening of a conference presentation in which the speaker strives to prove her satisfaction to be part of the event. The orthographic transcript is offered in table 6 :

\section{$<$ INSERT TABLE 6 HERE $>$}

The speaker uses intense language that focuses on emotions (e.g. "excited to be here", "close to our hearts", "happy to present it today"). As in the previous examples, this emotionally intense language contributes to rapport. She also evaluates her and her copresenter's research in positive terms using words that again appeal to emotions rather than reasoning ("very important research", "exciting way to work", "growing in popularity", "really interesting"). According to the speaker both evaluative and emotional language are connected to a need to make sure that the topic is presented as "valuable, valued, and authentic". As she explained, she wanted to convey "this is something we care about, so we hope you care about it too".

The speaker also uses two references to the title of the conference ("The Ins and Outs of Professional Discourse") both at the beginning and the end of the excerpt, providing a circular structure. This circular structure together with a three part list when she describes what undergraduates do (develop research question, collect data, present findings) provide emphasis and contribute to make the text memorable (Bowring et al., 2013).

According to the speaker, the references to the event are intentional, because she was not sure whether the audience would see the connection of her presentation with the topic of the conference. The second time she pronounces "ins and outs" both hands move in OHS lateral beats, as figures $6 \mathrm{a}$ and $6 \mathrm{~b}$ below show, visually signalling the contrast established (gestural processing aid).

\section{<INSERT FIGURE 6a HERE> <INSERT FIGURE 6b HERE>}

The beats are synchronous with the prominences: 'INS', 'AND' (see table 7). This use of prominence is interesting, because it emphasizes the coordinating conjunction 'and', providing a sense of duality (paraphrasable by "not only ins, but also outs"). The 
speaker explained in the interview that this is a consequence of the way she interpreted the call for abstracts, which seemed to indicate expectations of papers focusing on either one aspect or the other, while hers focused on both and she felt the need to justify this. With this ensemble she facilitates understanding of her message, but more importantly, also builds rapport and shows how her research fits in the conference, which is crucial to present her message as 'interpersonally acceptable' in the context of the conference (Hyland, 1997: 440).

\section{$<$ INSERT TABLE 7 HERE $>$}

The speaker uses intonation to project the context of interaction. A high termination in 'communities' in unit 29 , reinforced by an immediately following pause, presents this concept as innovative, contrasting with the fall tone and mid key of the final utterance which prompts concurrence and presents the suggestion of understanding communities in a broader sense as reasonable. Interestingly, the concept of 'broader' is clarified by circular movement with open hands that expands outwards (gestural processing aid), as figure 7 shows.

\section{$<$ INSERT FIGURE 7 HERE $>$}

Summing up, the speaker evaluates, emphasizes and builds rapport through words, facilitates understanding through gestures, and uses intonation to emphasize parts of her message and present ideas as innovative, reasonable or already agreed upon. The use of modes and strategies are represented in figures $8 \mathrm{a}$ and $8 \mathrm{~b}$ respectively.

A recurring idea that kept coming back in the interview with this speaker is an awareness of "belonging to a different community" where research is done differently. As she puts it, "we come from different academic cultures" and have different "research practices". This translates into noticeable efforts to fit in, which become evident in the explicit references to the event. The rapport-building also has to do with "knowing I was an outsider in that community, so, I'm just making sure that, it's building the rapport to show that I was happy to be there even if our work is a little bit different, maybe." In short, the speaker thinks her way of presenting reveals that "there was a lot about making sure people understood why we were there, that we fit, and that the work we do was valid and rigorous (...)".

Comparative overview of multimodal persuasion in the three examples 
Table 8 presents an overview of the use of multimodal strategies in the three excerpts discussed above.

\section{<INSERT TABLE 8 HERE>}

One of the most widely used strategies in the three examples is rapport. It is realised through gestures and words in the product pitch and research dissemination talk, but restricted to words in the conference presentation. In conferences rapport tends to take the form of peer approval and institutional recognition (Hyland 2009), which are apparently more easily conveyed through words.

Emphasis is also used extensively in the three examples, but is more frequent and more multimodal in the product pitch. As literature on product pitches suggests and the speakers themselves expressed in the interviews, a main concern of pitches is to draw attention to the unique selling point (USP) of the product, which is easily achieved multimodally through emphasis.

Processing aids are also more frequent and more multimodal in the research dissemination talk, which seems to respond to a wider knowledge gap with the audience. Attention getting is also exclusively present in the dissemination talk. This may be due to a lower intrinsic interest in the topic from the part of the audience.

The results show that multimodal persuasive ensembles are not exclusive of any of the three genres: in the three cases presented we see emphasis through words and intonation. On the other hand, it is also interesting to note that very similar multimodal ensembles can contribute to different persuasive strategies and have different communicative effects. A clear example of this is the pointing gesture with an extended finger coupled with direct addresses to the audience that is used in both the product pitch and the dissemination talk. In the product pitch it is meant to emphasize a problem and create rapport showing how this problem can affect the audience. According to the literature, this can work as a persuasive appeal in product pitches (Bamford 2007, 2008; Bowker, 2007; Burzynski's, 2013; Clemence Lepers, 2015; Woods et al., 2014). In the dissemination talk it is mainly an attention getting technique that is meant to be surprising and prompt heuristic-based persuasion (Perloff, 2003).

These findings support previous research that claims that every presentation is designed for a particular audience, what in CA is called the principle of 'recipient design' 
(Rendle-Short, 2006). Research also proves that this adaptation to the audience is a prerequisite to achieve persuasion (O'Keefe, 2002; Perloff, 2003; Hyland, 2005; Benoit \& Benoit, 2008; Simons \& Jones, 2011). The MDA analysis applied to the examples discussed in this paper reveals how this adaptation concerns not only the linguistic element in communication, but rather a whole multimodal ensemble including modes such as intonation and gestures among others. Therefore, to answer the research question that steered this study, the findings suggest that speakers adapt to the their audiences creating a different relationship with them and that this is reflected in their use of multimodal persuasive strategies.

\section{Conclusions}

One of the main conclusions that can be drawn from this study is that the type of relationship that is established with the audience seems to stand out as a defining trait of each genre. The stance of the product pitches in the corpus analysed can be summarised as "you have a problem, I have the solution for you". Research dissemination talks present research as relevant for the audience, and their underlying message can be paraphrased as "my research is relevant for you". Finally, in conference presentations speakers often request to be accepted as competent members of the scientific community, in what could be worded as "my research is valid and in line with what the rest of you do". Furthermore, this difference seems to be more telling in terms of genre differentiation than the differences in the specific strategies speakers select to persuade their audiences or the semiotic modes that they choose to enact them. As the examples discussed have shown, the same persuasive strategy realised through the same semiotic mode can work equally well in the three genres, as long as it promotes the appropriate interpersonal relationship. Likewise, the same multimodal ensemble can be used to enact different persuasive strategies in each case. It follows from this that the starting point in the design of an effective, persuasive presentation should be the audience, rather than the selection of modes or strategies, which should be ancillary to audience.

The results of this study support the idea that the right interpersonal relationship is a crucial element to pave the way for persuasion, as pointed out by Benoit \& Benoit (2008) or Simons \& Jones (2011). The real contribution of a multimodal approach is that it allows us to see how every mode at play (including the ones which are less frequently studied and less consciously applied, like a gesture or a particular use of 
intonation) can contribute to build this relationship. In fact, a skilful orchestration of modes into a multimodal ensemble can prove very effective, because when this ensemble is coherent and consistent, the overall effect becomes larger than the sum of each semiotic mode. A subtle gesture such as a lateral beat might not be immediately regarded as persuasive, but it is endowed with this persuasive effect once it is embedded in the ensemble and contributes to the right relationship with the audience.

The study presented in this paper is too modest in terms of size and scope to aim at generalisability. Larger-scale studies including more complex multimodal ensembles are needed to investigate the contribution of other modes that are crucial in these presentations (e.g. visuals or face expression). Likewise, larger corpora would open the door to quantitative analysis and pave the way for results that could be more safely generalised. Such studies would greatly contribute to our understanding of persuasion in presentations.

\section{References}

Anderson, C. (2013). How to Give a Killer Presentation. Harvard Business Review. Retrieved February, 2017 from https://hbr.org/2013/06/how-to-give-a-killerpresentation.

Bamford, J. (2007). Accentuating the positive. Evaluation and persuasive discourse in business presentations. In J. Bamford, R. Salvi \& J. Bowker (Eds.), Business Discourse: Language at work (pp. 135-155). Aracne Editrice.

Bamford, J. (2008). Telling a convincing story: a corpus assisted analysis of business presentations. In A. Martelli \& V. Pulcini (Eds.), Investigating English with corpora. Studies in honour of Maria Teresa Prat (pp. 277-291). Polimetrica.

Bavelas, J., Chovil, N., Coates, L., \& Roe, L. (1995). Gestures specialized for dialogue. Personality and Social Phychology Bulletin, 21(4), 394-405.

Benoit, W. \& Benoit, P. (2008). Persuasive messages. The process of influence.Oxford: Blackwell.

Bhatia, V. (2005). Generic patterns in promotional discourse. In H. Halmari \& T. 
Virtanen (Eds.), Persuasion across genres (pp. 213-228). John Benjamins.

Bowker, J. (2006). Referential and and affective force in oral business presentations: The role of narration. In J. Bamford \& M. Bondi (Eds.), Managing interaction in professional discourse: Intercultural and interdiscoursal perspectives (pp. 58-71). Rome: Officina.

Bowker, J. (2007). Uncovering intentionality and the process of persuasion in oral business narratives. In J. Bamford \& R. Salvi (Eds.), Business Discourse: Language at work (pp. 47-87). Rome: Aracne Editrice.

Bowring, M., Carter, R., Goddard, A., Reah, D., \& Sanger, K. (2013). Working with Texts: A Core Introduction to Language Analysis. Taylor \& Francis.

Brazil, D. (1997). The communicative value of intonation in English (2nd ed.). Cambridge: Cambridge University Press.

Burzynski, J. (2013). Elements of a Successful Product Pitch. Retrieved October 10, 2016, from http://38pitches.com/elements-of-a-successful-product-pitch/

Caliendo, G. (2014). The popularisation of science in web-based genres. In G. Caliendo \& G. Bongo (Eds.), The language of popularisation: Theoretical and Descriptive models (pp. 101-132). Bern: Peter Lang.

Carter-Thomas, S., \& Rowley-Jolivet, E. (2003). Analysing the Scientific Conference Presentation (CP): A Methodological Overview of a Multimodal Genre. ASp: La Revиe Du GERAS, 40(39-40), 59-72.

Chesterman, A. (1998). Contrastive functional analysis. Amsterdam: John Benjamins.

Compagnone, A. (2015). The Reconceptualization of Academic Discourse as a Professional Practice in the Digital Age : A Critical Genre Analysis of TED Talks. Journal of Language and Communication in Business, (54), 49-69.

Dalton, C., \& Seidlhofer, B. (1994). Pronunciation. Oxford: Oxford University Press.

Heath, C. \& Heath, D. (2007) Made to stick: Why some ideas survive and others die. New York: Random House.

Hyland, K. (1997). Scientific Claims and Community Values: Articulating an Academic 
Culture. Language and Communication, 17(1), 19-32.

Hyland, K. (2005). A Convincing Argument: Corpus Analysis and Academic Persuasion. In U. Connor and T. Upton (Eds.), Discourse in the Professions: Perspectives from Corpus Linguistics (pp. 87-114). Amsterdam: Benjamins.

Hyland, K. (2009). Academic Discourse. London: Continuum.

Kast, B. (2008). iKeynote-Representation, rhetoric and visual communication by Steve Jobs in his keynote ar Macworld 2007. University of Salzburg.

Kendon, A. (2004). Gesture: Visible action as utterance. Cambridge: Cambridge University Press.

Lakoff, R. (1982). Persuasive discourse and ordinary conversation, with examples from advertising. In D. Tannen (Ed.), Analysing discourse: text and talk (pp. 25-42). Washinton: Georgetown University Press.

Lepers, C. (2015). How To Pitch an Idea in 7 Steps. Retrieved October 10, 2016, from http://www.pptpop.com/how-to-pitch-an-idea/

Lichinski, A. (2008). Examples as persuasive arguments in popular management literature. Discourse and Communication, 2(3), 243-269.

Masi, S. (2016). Gestures in motion in TED Talks: Towards a Multimodal Literacy. In Bongsinori, L. \& Crawford Camiciottoli, B. (Eds.), Multimodality across communicative settings, discourse, domains and genres (pp. 146-165). Cambridge Scholars Publishing.

McGregor, A., Zielinski, B., Meyers, C., \& Reed, M. (2016). An exploration of teaching intonation using a TED Talk. In J. Levis, H. Le, I. Lucic, E. Simpson, \& S. Vo (Eds.), Proceedings of the 7th Pronunciation in Second Language Learning and Teaching Conference (pp. 143-149). Iowa State University.

McNeill, D. (1992). Hand and mind. University of Chicago Press.

Norris, S. (2004). Analysing Multimodal Interaction: A Methodological Framework. London \& New York: Continuum. 
Norris, S. (2011). Identity in (inter)action. introducing multimodal (inter)action analysis Boston: De Gruyter Mouton.

Morell, T. (2015). International conference paper presentations: A multimodal analysis to determine effectiveness. English for Specific Purposes, 37, 137-150.

Niebuhr, O., Voße, J., \& Brem, A. (2016). What makes a charismatic speaker? A computer-based acoustic-prosodic analysis of Steve Jobs tone of voice. Computers in Human Behavior, 64, 366-382.

O’Keefe, D. (2002). Persuasion: Theory and research. London: Sage Publications.

Petty, R., \& Cacioppo, J. (1977). Forewarning, Cognitive Responding and Resistance to Persuasion. Journal of Personality and Social Psychology, 35, 645-55.

Poggi, I., \& Pelachaud, C. (2008). Persuasion and the Expressivity of Gestures in Humans and Machines. In I. Wachsmuth, M. Lenzen, and G. Knoblich (Eds.), Embodied communication in humans and machines (pp. 45-67). Oxford University Press.

Perloff, R. (2003). The dynamics of persuasion. London: L. E. Associates

Pomerantz, A. (1986). Extreme case formulations: A way of legitimizing claims. Human Studies, 9, 219-229.

Simons, H. \& Jones, J. (2011). Persuasion in Society. $2^{\text {nd }}$ edition. New York: Sage.

Sinclair, J. (2005). Corpus and Text -Basic Principles. In M. Wynne (Ed.) Developing linguistic corpora: a guide to good practice Oxford (pp. 1-16). Oxbow Books.

Querol-Julián, M. (2011). Evaluation in Discussion Sessions of Conference Paper Presentations: A Multimodal Approach. LAP Lambert Academic Publishing GmbH \& Co. K.G.

Rackham, N. (1998). From Experience: Why bad things happen to good new products. Journal of Product Innovation Management, 12, 201-207.

Räisänen, C. (2002). The conference forum: A system of interrelated genres and discursive practices. In E. Ventola, C. Shalom, \& S. Thompson (Eds.), The language of conferencing (pp. 69-93). Frankfurt: Peter Lang. 
Rendle-Short, J. (2006). The Academic Presentation: Situated Talk in Action. Ashgate.

Rowley-Jolivet, E. (1999). The pivotal role of conference papers in the network of scientific communication. ASp, 26, 179-196

Rowley-Jolivet, E., \& Carter-Thomas, S. (2005). The rhetoric of conference presentation introductions: context, argument and interaction. International Journal of Applied Linguistics, 15(1), 45-70.

Scotto di Carlo, G. (2014). Ethos in ted talks : The role of credibility in popularised texts. Facta Universitatis, 12, 81-91.

Swales, J. M., \& Burke, A. (2003). "It's really fascinating work": Differences in Evaluative Adjectives across Academic Registers. In P. Leistyna \& C. F. Meyer (Eds.), Corpus Analysis: Language Structure and Language Use (pp. 1-18). Amsterdam and Atlanta: Rodopi.

Thompson, S. (2002). "As the story unfolds": The uses of narrative in research presentations. In E. Ventola, C. Shalom, \& S. Thompson (Eds.), The language of conferencing (pp 147-167). New York: Peter Lang.

Woods, R., Rafferty, K., Murphy, J., \& Hermon, P. (Eds.). (2014). Engineering innovative products. John Wiley.

Wulff, S., Swales, J. M., \& Keller, K. (2009). "We have about seven minutes for questions": The discussion sessions from a specialized conference. English for Specific Purposes, 28(2), 79-92.

\section{TABLES}

Table 1a Annotation conventions for DI

\begin{tabular}{|l|l|l|}
\hline \multicolumn{2}{|l|}{ Tone unit= ONSET (first prominent syllable) + TONIC (last prominent syllable) } \\
\hline $\begin{array}{c}\text { Tone: pitch movement } \\
\text { in tone unit }\end{array}$ & $\begin{array}{l}\text { Key: relative pitch of onset } \\
\text { syllable }\end{array}$ & $\begin{array}{l}\text { Termination: relative pitch } \\
\text { of tonic syllable }\end{array}$ \\
\hline Fall & High key: superscript & High termination: superscript \\
\hline Level $\longrightarrow$ & Mid key: normal font & Mid termination: normal font \\
\hline
\end{tabular}




\begin{tabular}{|l|l|}
\hline Rise & Low key: subscript \\
\hline Example: \\
which TELLS you which in ${ }^{\mathrm{GRE}}$ dients you are going to use \\
This is a tone unit with mid key, high termination and fall tone \\
Note: for the sake of clarity tone is only included when relevant for the analysis and \\
discussion of results.
\end{tabular}

Table 1b Annotation conventions for Gestures

\begin{tabular}{|c|c|c|}
\hline Gesture family: & Gesture type: & Gesture function: \\
\hline $\begin{array}{l}\text { R: ring } \\
\text { (Kendon, 2004) }\end{array}$ & $\begin{array}{l}\text { I: iconic (represent concrete } \\
\text { objects and events ) } \\
\text { (McNeill, 1992) }\end{array}$ & $\begin{array}{l}\text { R: referential (represent some } \\
\text { aspect of the content) } \\
\text { (Kendon, 2004) }\end{array}$ \\
\hline $\begin{array}{l}\text { G: grappollo (finger bunch) } \\
\text { (Kendon, 2004) }\end{array}$ & $\begin{array}{l}\text { M: metaphoric (represent } \\
\text { abstract ideas) } \\
\text { (McNeill, 1992) }\end{array}$ & $\begin{array}{l}\text { I: interpersonal (regulate } \\
\text { interaction ) } \\
\text { (Bavelas et al., 1995) }\end{array}$ \\
\hline $\begin{array}{l}\text { OHP: open hand prone } \\
\text { (palms down) } \\
\text { (Kendon, 2004) }\end{array}$ & $\begin{array}{l}\text { B: beat (repetitive gestures } \\
\text { that usually mark the } \\
\text { discourse flow) } \\
\text { (Kendon, 2004; Bavelas et al. } \\
\text { 1995) }\end{array}$ & $\begin{array}{l}\text { P: pragmatic } \\
\text { (show attitude } \\
\text { perlocutionary meaning) } \\
\text { (Kendon, 2004) }\end{array}$ \\
\hline $\begin{array}{l}\text { OHS: open hand supine } \\
\text { (palms up) } \\
\text { (Kendon, 2004) }\end{array}$ & $\begin{array}{l}\text { D: deictic (point to } \\
\text { something) } \\
\text { (Kendon, 2004) }\end{array}$ & $\begin{array}{l}\text { C: cohesive } \\
\text { (link parts of discourse ) } \\
\text { (McNeill, 1992; Querol, 2011) }\end{array}$ \\
\hline CF: close fist & & \\
\hline
\end{tabular}

Table 2 Orthographic transcription product pitch

You have an app. That app is important to your business, important to your business success. Because of that, you care about how your users experience that app, and you care about how your users feel about that app. But sometimes, you deliver a bad experience. Sometimes, you deliver a real bad experience. 
Table 3 DI transcription product pitch

1. you HAVE an APP

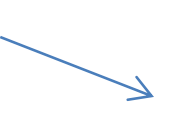

2. that APP is imPORtant to your business

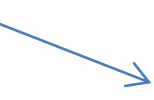

3. imPORtant to your business sucCESS

4. beCAUSE of THAT

5. you CARE about how your users exPErience that app

6. and you care about HOW your users FEEL about that app

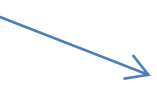

\section{4.}

.

7. but SOMEtimes you deliver a BAD experience
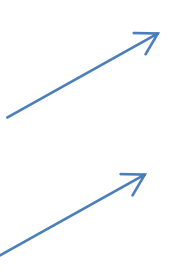

7.

8. SOMEtimes you deliver a REAL bad experience
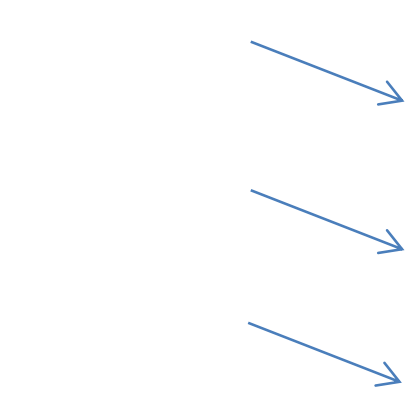

Table 4 Orthographic transcription research dissemination talk

Hi. I'm a chemist, and I really like kissing. I'd like to kiss you, I'd love to kiss you, I'm gonna kiss all of you. Because I really want to keep it simple, but not stupid. Tonight I'm going to show you how your own experience, with a very simple technique, can revolutionise the chemical industry, and finally, your life.

Table 5 DI transcription research dissemination talk

\begin{tabular}{|ll|}
\hline 1. & HI \\
2. & I'M a CHEmist \\
3. & and i REally like KIssing \\
4. & i'd LIKE to KISS you \\
5. & i'd LOVE to KISS you \\
6. & i'm GOnna kiss ALL of you \\
7. & beCAUSE \\
8. & i REAlly want to \\
\hline
\end{tabular}




\begin{tabular}{|ll|}
\hline 9. & KEEP it SIMple \\
10. & but NOT stupid \\
11. & toNIGHT \\
12. & i'm going to SHOW you how your OWN experience \\
13. & with a VEry simple technique \\
14. & can revoLUtionise the CHEmical industry \\
15. & and FInally YOUR life \\
\hline
\end{tabular}

Table 6 Orthographic transcription conference presentation

We're very excited to be here in this conference because the theme, "Ins and Outs of Professional Discourse," is very close to our hearts as we've been working for the last two years on Kelsey's very important undergraduate research project. And to give you a little information about undergraduate research in the United States, it's a movement of engaged learning where undergraduates like Kelsey develop their own research questions, collect their own data and present their own findings under the mentorship of the faculty members. So they are doing the same work that a Master's or a PhD level student would do with the same kind of mentorship, presenting at conferences, publishing their work, so it's a very exciting way to work with undergraduate students and it's growing in popularity in America. Kelsey's project is really interesting and we're happy to present it today, in that it deals with both the ins and outs and a different way of thinking about how we enter communities and a broader sense of community that we can address.

Table 7 DI transcription conference presentation

\begin{tabular}{|ll|}
\hline 1. & we're very exCIted to be HERE in this conference \\
2. & because the THEME \\
3. & INS and OUTS of professional DIScourse \\
4. & is very CLOSE to our HEARTS \\
5. & as we've been WORking for the last two years on KELsey's \\
6. & eh \\
7. & VEry important \\
8. & underGRAduate research PROject \\
9. & and to give you a little information aBOUT underGRAduate research in the united states \\
10. & it's a \\
11. & it's a MOVEment of engaged LEARning \\
12. & where underGRAduates LIKE kelsey \\
13. & deVElop their own reSEARCH questions \\
14. & colLECT their own DAta \\
15. & and preSENT their own FINdings \\
16. & under the MENtorship of the FAculty members \\
17. & so they are DOING the SAME work \\
18. & that a MASter's or a PHD level student
\end{tabular}




\begin{tabular}{|ll|}
\hline 19. & WOULD do \\
20. & with the SAME kind of MENtorship \\
21. & preSENting at CONferences \\
22. & PUblishing their WORK \\
23. & so it's a very exCIting way to WORK with undergraduate students \\
24. & and it's GROwing in popuLARity in america \\
25. & KEL sey's project is really INteresting \\
26. & and we're HAPpy to present it toDAY \\
27. & in that it deals with both the INS AND outs \\
28. & and a DIFFerent way of thinking aBOUT \\
29. & how we ENter com \\
30. & and a BROADer sense of community that we can adDRESS \\
\hline
\end{tabular}

Table 8 Overview of multimodal strategies in the three genres

\begin{tabular}{|c|c|c|c|}
\hline & PP & DT & $\mathbf{C P}$ \\
\hline Attention getting & & & \\
\hline Emphasis & & & \\
\hline Evaluation & & & \\
\hline Processing aids & & & \\
\hline Projection & & & \\
\hline Rapport & & & \\
\hline
\end{tabular}

\section{FIGURE LEGENDS}

Figure 1 Annotation with ELAN

Figure 2 Beats with extended fingers in product pitch

Figure 3a Multimodal ensemble in product pitch

Figure 3b Use of strategies in product pitch

Figure 4a Deictic gestures with extended finger in research dissemination talk

Figure 4b Deictic gestures with open hands in research dissemination talk 
Figure 5a Multimodal ensemble in dissemination talk

Figure $5 \mathbf{b}$ Use of strategies in dissemination talk

Figure 6a Lateral beats in conference presentation

Figure 6b Lateral beats in conference presentation

Figure 7 Circular movement with open hands in conference presentation

Figure 8a Multimodal ensemble in conference presentation

Figure 8b Use of strategies in conference presentation 